\section{Lucas F. Tamagno}

lucastamagno@hotmail.com

Recibido: 30.09 .20

Aceptado: 09.12.20

\title{
El contrato de trabajo eventual en Argentina
}

\section{Temporary employment contracts in Argentina}

Resumen: El contrato de trabajo eventual en Argentina se presenta como una modalidad contractual laboral de carácter extraordinario y excepcional, ya que el principio general que rige en materia laboral en este país es que los contratos de trabajo se celebran a tiempo indeterminado. El presente trabajo tiene por objeto realizar una breve descripción de las características que presenta el contrato de trabajo eventual en Argentina, partiendo desde el momento de su dictado, demarcado por un proceso de flexibilización laboral para luego iniciar un análisis desde los aspectos normativo, doctrinario y jurisprudencial, y finalmente brindar una posición propia respecto de esta modalidad contractual que ha sido tan atacada por la Justicia del Trabajo.

Palabras clave: contrato de trabajo; derecho laboral argentino; contrato de trabajo eventual.
Abstract: Since the general principle governing labor matters in Argentina is that employment contracts are entered into an indefinite term, the temporary employment contract is an extraordinary and exceptional type agreement. The purpose of this paper is to make a brief description of the characteristics of the temporary employment contract in Argentina, starting from the moment of its enactment, marked by the process of labor flexibilization. Then, present an analysis from the normative, doctrinal and jurisprudential aspects and finally provide a position regarding this contractual modality that the Labor Courts have so attacked.

Keywords: employment contract; Argentine labor law; temporary employment contract. 
El contrato de trabajo como tal ha ido logrando su desarrollo con el correr del tiempo, tanto en materia de doctrina, como en materia judicial y en la recepción y desarrollo desde el punto de vista legislativo. Esto es claramente apreciable de la propia búsqueda de antecedentes en los primeros libros que se encargaban de analizar el derecho del trabajo en Argentina, ello a partir de obras de destacados autores como fueron Alejandro Unsaín, Luis Despontín, Juan Ramírez Gronda, entre otros.

En sus orígenes muchos contratos laborales eran regulados por el Derecho clásico de corte civilista, y a través de la locación de servicio y la locación de obra se enmarcaban contratos por fuera del derecho laboral, cuando en la realidad se trataban de relaciones subordinadas. Incluso "juristas de alto prestigio, como Planiol, objetaron al comienzo, un distinto enfoque y procuraron demostrar que la denominación «contrato de trabajo» era falsa desde el punto de vista jurídico, ya que el trabajo puede ser objeto de varios contratos diferentes: locación, empresa, sociedad, prestación gratuita" (Ramirez Gronda, 1964, p. 413).

Poco a poco se fue abandonando esa posición de corte más liberal y se comenzó a pensar más en un contrato con mayor protección a la figura del trabajador, para poder evitar así los abusos que sufrían en ese entonces. Ya con un contrato laboral caracterizado como tal, se comenzó con una clasificación en la que se podían encontrar dos tipos de contratos en material laboral, el contrato a tiempo determinado o a plazo y el contrato a tiempo indeterminado, dependiendo únicamente de que en el mismo se fijara un término de vigencia para el mismo. Pero más allá de ello, también se presentaban situaciones de interpretación dudosa, tales los casos de contratos en donde se fijaba como término un hecho determinado como podía ser la cesación del período de guerra o la cesación de relación social. Destacaba el autor italiano Luigi De Litala (1946) que "[e]n estos casos es evidente que, siendo incierto cuándo terminará la guerra, cuándo cesará la relación social existente entre extraños a la relación de empleo, el contrato de empleo es por tiempo indeterminado; mientras si la obra no está precisada, entonces existe una absoluta falta de certeza del término, y por consiguiente, el contrato es por tiempo indeterminado" (p. 189).

Con el desarrollo del derecho laboral, y con la influencia que tuvo en Argentina el constitucionalismo social, se comenzó a tomar al trabajador como un sujeto de preferente tutela, y fue así que años después con el dictado de la Ley de Contrato de Trabajo (LCT) se estableció el principio de indeterminación de los plazos como principio general que rige en materia contractual en las relaciones laborales, lo cual fue receptado en el primer párrafo de su artículo 90, principio general que autores como los españoles Alonso Olea y Casas Baamonde (1987, p. 206) ubican dentro de la derivación del principio general de derecho contractual de conservación del negocio.

Hoy en Argentina el principio general es que los contratos laborales son celebrados a tiempo indeterminado ${ }^{1}$ a menos que las partes adopten alguna otra modalidad contractual de carácter excepcional, para lo cual los mismos deberán ser celebrados por escrito y cumpliéndose con una serie de requisitos y condiciones que detallaremos seguidamente.

La LCT tiene por objeto regular las relaciones laborales entre empleado y empleador, y más allá de que posee normas complementarias, a través de ella se intentó establecer normativamente las distintas situaciones que rodean al contrato de trabajo. En este esquema el legislador le dedicó un título -ya que la ley está dividida en títulos y a su vez los títulos en capítulos - a las diferentes modalidades contractuales.

Así el Título III de la LCT llevo el nombre de "De las modalidades del contrato de trabajo" y en él se regularon las distintas modalidades contractuales que rigen en Argentina. El título comienza con la descripción del principio general de indeterminación de los plazos, al cual

\footnotetext{
${ }^{1}$ Lo que en palabras de Antonio Vázquez Vialard (1978, p. 216) definía como una forma de contratación preferida por la ley.
} 
hacíamos referencia anteriormente, y dentro de dicho título cada capítulo se encarga de regular los distintos contratos que pueden celebrarse entre empleado y empleador, dentro de los cuales encontramos al contrato de trabajo eventual.

La Ley $24.013^{2}$, dictada en el marco del período que se conoce como "flexibilización laboral" en la década de 1990, efectuó diferentes modificaciones a la LCT intentando incorporar figuras contractuales necesarias para la promoción del empleo, pero fue atacada desde diversos ámbitos políticos y jurídicos, por cuanto sostenían sus detractores que era una ley que precarizaría -y muchos hoy lo siguen sosteniendolas relaciones laborales, justamente por incorporar este tipo de contrataciones a las que denominaron "contratos basura".

La idea del legislador en aquel momento fue la de crear nuevas modalidades contractuales con el objetivo de generar puestos de trabajo, ya que mediante la implementación de este tipo de contratos los empleadores no tenían que abonar indemnizaciones una vez finalizada la relación laboral.

Se sostenía en aquel entonces que "[e]sta nueva Ley, pese a no establecerlo en forma concreta, tiene un innegable carácter de orden público por lo que sus disposiciones sustituyen, derogan, modifican o complementan las de la Ley de Contrato de Trabajo y, en consecuencia, deben interpretarse armónicamente con ellas" (Etala, Etala \& De Virgilis, 1992, p. 1).

Lo cierto es que veintiocho años después del dictado de la norma los artículos que regulan este tipo de contratos no han sido derogados y siguen vigentes, aunque la Justicia del Trabajo en muchas ocasiones los ha descalificado, conforme se verá más adelante.

\section{Caracterización del contrato de trabajo eventual}

La propia Real Academia Española (2014) incluye esta modalidad contractual al brindar la definición del término eventual, ello surge cuando en su cuarta acepción refiere: "Dicho de un trabajador: Que no pertenece a la plantilla de una empresa y presta sus servicios de manera provisional". Y es justamente en España donde aparecen los antecedentes sobre los cuales se asentó el Poder Legislativo argentino, tomando para ello el Estatuto de los Trabajadores de dicho país, conforme se establece en el art. 15.1, inciso b), del referido cuerpo legal. En particular, se dispone que, entre otros supuestos, podrá celebrase un contrato de duración determinada "cuando las circunstancias del mercado, acumulación de tareas o exceso de pedidos así lo exigieran, aun tratándose de la actividad normal de la empresa"3. Cruz Villalón (2019) sostiene que "se trata de una modalidad tradicional entre los contratos temporales causales, justificada su celebración en una necesidad de incremento de mano de obra por parte de la empresa por circunstancias del mercado o acumulación de tareas, con independencia que se trate o no de actividad normal de la empresa" y concluye así que es "un dato cuantitativo de empleo

\footnotetext{
2 Promulgada el 13 de noviembre de 1991.

${ }^{3}$ A su vez el art. 15.1 b) añade: "En tales casos, los contratos podrán tener una duración máxima de seis meses, dentro de un periodo de doce meses, contados a partir del momento en que se produzcan dichas causas. Por convenio colectivo de ámbito sectorial estatal o, en su defecto, por convenio colectivo sectorial de ámbito inferior, podrá modificarse la duración máxima de estos contratos y el periodo dentro del cual se puedan realizar en atención al carácter estacional de la actividad en que dichas circunstancias se puedan producir. En tal supuesto, el periodo máximo dentro del cual se podrán realizar será de dieciocho meses, no pudiendo superar la duración del contrato las tres cuartas partes del periodo de referencia establecido ni, como máximo, doce meses".
} 
y no cualitativo el que justifica la contratación" (p. 192). En este sentido, la necesidad para recurrir a esta clase de contrato tiene que fundarse en circunstancias objetivas, como, por ejemplo, sería "la concurrencia de un cierto plus como puede resultar (...) de un concreto y específico encargo que conlleve un incremento inusual de la actividad de la empresa" (Mercarder Uguina, 2018, p. 293).

Ahora bien, volviendo a la situación argentina, si bien el contrato de trabajo eventual no estaba regulado con anterioridad a la sanción de la ley 20.744 en forma específica como lo está hoy, la legislación y la jurisprudencia de los tribunales del trabajo habían anticipado esta modalidad contractual. Así, el decreto 33.302/45 establecía en su art. 2 que se consideraba empleado u obrero a toda persona que realizara "tareas en relación de dependencia para uno o varios empleadores, alternativa, conjunta o separadamente, en forma permanente, provisoria, transitoria, accidental o supletoria". De esta forma en el contrato ya se hablaba de la existencia de una relación de dependencia transitoria o provisoria, dentro de la cual se podría encuadrar un esquema contractual similar al del contrato eventual.

Así es que luego primero del dictado del decreto 33.302/45, y luego con el dictado de la Ley 24.013, encontramos al contrato de trabajo eventual dentro del encuadre normativo, el cual se encuentra contemplado en el art. 99 de la LCT.

El contrato de trabajo eventual es un contrato de carácter temporalmente transitorio y generado por una tarea extraordinaria, propia o no del giro empresario ${ }^{4}$, en donde se supera cuantitativamente la capacidad de la empresa, y que culmina con el agotamiento del objeto que motivó su contratación, ya sea la realización de una obra determinada, la ejecución del acto o la prestación del servicio para el que fue contratado y que tiene como nota distintiva la imposibilidad de conocer el plazo de finalización al momento de llevarse adelante la contratación. Lo importante es que ese trabajo para el cual es contratado el empleado no tenga perspectiva de continuidad o permanencia.

En la práctica habitual este tipo de contratación se utiliza para reemplazar licencias de otros trabajadores permanentes de la empresa - lo que se conoce en doctrina laboral como contrato de interinidad $-{ }^{5}$, para atender picos estacionales o extraordinarios de trabajo o por circunstancias extraordinarias que normalmente no pueden ser previstas por el empresario o que no se suceden con habitualidad en el desarrollo de la actividad empresarial.

En este sentido la ley 24.013 establece en su art. 69 que para el caso de que el contrato de trabajo eventual tenga por objeto sustituir a un trabajador permanente por un período de licencia, deberá identificarse en el contrato que se suscriba al trabajador a reemplazar.

El art. 72 de la ley mencionada en el párrafo anterior establece que en los casos en los que el contrato tenga por objeto atender circunstancias extraordinarias deberá consignarse en el contrato, con total precisión, las circunstancias que lo motivan, y si bien en materia laboral los contratos de trabajo en Argentina no requieren de ninguna formalidad ni celebración de contrato por escrito, en el caso de los contratos excepcionales, como el contrato de trabajo eventual, este principio se convierte

\footnotetext{
${ }^{4}$ Aunque vale destacar que muchos jueces sostienen, a nuestro entender de forma errada, que solo podrá existir un contrato de trabajo eventual cuando las tareas para las cuales se contrata al empleado no sean propias del giro normal y específico de la empresa.

${ }^{5}$ Y nos referimos en este caso a reemplazar a otros empleados en licencia, ya que no se podría configurar este supuesto de excepción cuando la suplencia es por un cambio de estructura de la empresa, por movilidad interna, por reemplazar a otro empleado que fue ascendido. Así fue sostenido por la Justicia del Trabajo al decir que "si la actora fue contratada para reemplazar a trabajadores permanentes, que fueron designados para realizar un proyecto informático en otro país, las tareas que desempeñó para la usuaria eran normales para la actividad bancaria y tampoco se había indicado exactamente a quién reemplazaba, no dándose ninguno de los presupuestos estipulados en el art. 3 del decreto 342/92. En el caso, el banco decidió asignar trabajadores permanentes para una tarea extraordinaria y suplir el trabajo permanente con personal eventual, lo que se encuentra vedado por los arts. 99 LCT y 69 de la LNE" (Cámara Nacional del Trabajo, Sala V, expte. n 19676/02, sentencia N 68396 del 28 de abril de 2006 en el caso "Aliotta, María c/ Citibank NA y otro s/ despido").
} 
en un requisito indispensable, sin el cual el contrato de trabajo no puede ser considerado eventual.

Incluso la Justicia del Trabajo ha sostenido en forma correcta $-y$ siguiendo los lineamientos dispuestos en la ley - que, en caso de no haberse cumplido con la formalidad de la existencia del contrato por escrito, no se podría siquiera adentrar en el análisis del contrato para verificar si efectivamente se trataba de un contrato de trabajo eventual de acuerdo a las circunstancias que lo motivaban. Así sostuvo al decir que "[a]l no existir una contratación instrumentada por escrito, no corresponde analizar si las razones tenidas en miras al momento de la contratación resultan o no encuadrables en los supuestos de eventualidad legalmente admisibles" ${ }^{\text {. }}$

A su vez el contrato eventual cuenta con una limitación temporal en cuanto a su duración, no pudiendo excederse de 6 meses por año ni de 1 año por el período de 3 años si se trataran de períodos interrumpidos o discontinuos. En caso de que se superen estos períodos el contrato se entenderá que el mismo se ha reconvertido a tiempo indeterminado en forma automática sin ningún tipo de interpelación por parte del trabajador.

El contrato eventual, como se expuso, es de carácter temporalmente transitorio, pero no tiene la posibilidad de fijarse un plazo determinado de tiempo, se trata de un contrato que hace referencia a una situación excepcional cuya duración no puede ser determinada al momento de la celebración del contrato, a diferencia de lo que sucede con otros contratos como el denominado "contrato a plazo fijo".

En este tipo de contrato los trabajadores eventuales carecen de estabilidad en el trabajo ${ }^{7}$, y por derivación de ello no tienen derecho a las indemnizaciones de ley como son la indemnización por preaviso e indemnización por antigüedad, de acuerdo con lo que expresamente establecen los arts. 73 y 74 de la Ley 24.013. El empleador deberá sí abonar los conceptos salariales correspondientes que son los días del mes en curso trabajado, el aguinaldo proporcional y las vacaciones proporcionales.

Como se expuso, una vez terminada la tarea eventual para la cual fue contratado el trabajador el mismo se extingue sin derecho indemnizatorio alguno, pero se plantea un interrogante respecto de qué sucede si el empleado es desvinculado con anterioridad a que se cumpla el objeto para el cual fue contratado. En estos casos por derivación de lo establecido en la segunda parte del art. 74 de la Ley 24.013 pareciera que cuando no se cumplan las previsiones contenidas en la primera parte del art. (motivo de finalización de la obra o tarea asignada, o del cese de la causa que le diera origen) se aplicarán las previsiones del art. 245 de la LCT que establece la cuantificación de la indemnización por antigüedad sumado al preaviso que el empleador debería haber otorgado, ya que el trabajador desconoce la finalización del contrato ante tempus, descartando - desde esta postura - que pueda exigirse otra indemnización adicional como los daños y perjuicios derivados de la ruptura anticipada.

\footnotetext{
${ }^{6}$ Cámara Nacional del Trabajo, Sala V, expte n 25232/03, sentencia № 69183 del 13 de febrero de 2007 en el caso "Jiménez, Patricia c/Apoyo laboral SRL s/despido".

${ }^{7}$ Es importante destacar en este sentido que en Argentina el empleo privado no cuenta con un régimen de estabilidad absoluta, sino que el empleador puede dar por finalizada la relación laboral con un empleado en cualquier momento sin expresión de causa, abonando únicamente los conceptos indemnizatorios previstos por la ley.
} 


\section{El contrato eventual y la contratación por intermedio de empresas de servicios eventuales}

Si bien el contrato de trabajo eventual ha sido usado como forma de contratación alternativa, el contrato que más se utiliza en la práctica en Argentina en materia de contratación eventual es el que se celebra a través de empresas de servicios eventuales.

Las empresas de servicios eventuales son empresas que suministran en calidad de empleador personal a empresas usuarias mediante la celebración de un contrato comercial. Así las empresas de servicios eventuales son empresas que tienen por único fin proveer de personal - a los cuales contratan con carácter permanente ${ }^{8}-$ a empresas que así se lo requieran, debiendo cumplir con una serie de requisitos técnicos y económicos, y a la vez encontrarse inscriptas ante un registro especial que se encuentra en manos del -hoy-Ministerio de Producción y Trabajo de la Nación para poder funcionar como tales. En caso de que no se cumplan con los requisitos formales señalados la contratación será considerada como fraudulenta ${ }^{9}$, conllevando consecuencias gravosas tanto para la empresa usuaria como para la empresa de servicios eventuales, conforme veremos seguidamente.

El art. 77 de la Ley 24.013 establece que las empresas de servicios eventuales deberán estar constituidas exclusivamente como personas jurídicas y con objeto único y sólo podrán mediar en la contratación de trabajadores bajo la modalidad de trabajo eventual.
De esta forma ingresa en el contrato de trabajo eventual una tercera persona que intermedia en la relación laboral, generándose así algunas diferencias entre el contrato de trabajo eventual puro y esta figura.

El contrato de trabajo eventual se suscribe entre un empleador y un trabajador en forma individual, mientras que en el caso de las empresas de servicios eventuales existe una doble contratación, por un lado una contratación entre una empresa de servicios eventuales y un trabajador y luego una segunda contratación, de carácter comercial, entre la empresa de servicios eventuales y la empresa usuaria de esos servicios, es lo que Fernández Madrid (2012) ha definido como "vinculaciones triangulares" (p. 517).

La empresa de servicios eventuales se encarga de proveer personal propio para el cumplimiento de las necesidades de la empresa usuaria, necesidades que también deben tener el mismo carácter de excepcionalidad que en el caso del contrato eventual ya descripto, por tratarse del mismo contrato, pero con el cumplimiento de las obligaciones principales en cabeza de la empresa prestadora del servicio.

A su vez, la Ley $N^{\circ} 24.013$ que incorporó esta figura contractual fue reglamentada mediante el decreto

\footnotetext{
${ }^{8}$ Y sobre los cuales tienen la posibilidad de reasignarlos a otros puestos de trabajo, conforme lo establece el decreto reglamentario de dicha ley, dec. $\mathrm{N}^{\circ} 342 / 92$. La empresa de servicios eventuales puede suspender las asignaciones para prestar servicios en el caso del trabajador con un límite temporal.

${ }^{9}$ En este sentido ha sostenido la Justicia del Trabajo que "[t]oda vez que la codemandada invocó en el responde que el actor fue contratado como personal permanente discontinuo, bajo la modalidad del decreto 342/92, era ella la encargada de demostrar que se encontraba habilitada para funcionar como proveedora de personal temporario y el único medio fehaciente para hacerlo es el informe del Ministerio de Trabajo, resultando insuficiente el dato proporcionado por la propia agencia al experto contable. Dado que los requisitos establecidos por el art. 29 LCT con acumulativos y no alternativos, al no haberse probado la existencia de uno de ellos, en el caso la existencia de un ente habilitado por la cartera laboral para funcionar como proveedora de trabajadores destinados a cumplir tareas eventuales) resulta inconducente analizar si, además, los servicios prestados por el accionante merecían o no el calificativo de eventuales" (Cámara Nacional del Trabajo, Sala X, expte. № 2/05, sentencia № 14407 del 20 de junio de 2006 en el caso "González, Víctor c/ Río de las Vueltas SRL y otro s/ despido).
} 
342/92, en el cual se estableció que la empresa de servicios eventuales podrá asignar trabajadores a las usuarias cuando los requerimientos de la segunda tengan por causa alguna de las siguientes circunstancias: a) en caso de ausencia de un trabajador permanente, durante el período de ausencia; b) en caso de licencias o suspensiones legales o convencionales, durante el período en que se extiendan, excepto cuando la suspensión sea producto de una huelga o por fuerza mayor, falta o disminución de trabajo; c) en caso de incremento en la actividad de la empresa que requiera, en forma ocasional y extraordinaria, un mayor número de trabajadores; d) en caso de organización de congresos, conferencias, ferias, exposiciones o programaciones; e) en caso de un trabajo que requiera ejecución inaplazable para prevenir accidentes, por medidas de seguridad urgentes o para reparar equipos del establecimiento, instalaciones 0 edificios que hagan peligrar a los trabajadores o a terceros, siempre que las tareas no puedan ser realizadas por personal regular de la empresa usuaria; y f) en general, cuando atendiendo a necesidades extraordinarias o transitorias hayan de cumplirse tareas ajenas al giro normal y habitual de la empresa usuaria.

De esta forma el legislador estableció en qué casos se podría contratar a través de empresas de servicios eventuales, aunque con la inclusión de un norma de tipo abierto como la prevista en el inciso f) habilitó la posibilidad de incluir cualquier actividad en la medida que la misma resultase extraordinaria o transitoria, e incluso permitiendo que ello así sea aún cuando las mismas resulten del giro normal y habitual de la empresa usuaria, algo que parecería contradecir la idea original del legislador.

Con relación al régimen de su contratación y las obligaciones que surgen del contrato, el trabajador proporcionado a una empresa usuaria a través de una empresa de servicios eventuales estará regido por el Convenio Colectivo de Trabajo de la actividad donde prestará tareas y será representado por el Sindicato y beneficiado por la Obra Social de la actividad o categoría en la que efectivamente preste servicios en la empresa usuaria. Por su parte la empresa usuaria deberá inscribir a este personal externo en un libro especial, sin que pueda entenderse por esto una relación laboral entre ellas.

Esta modalidad de contratación ha sido muy utilizada en Argentina, pero también ha presentado su faz patológica, y así fue pasible de condenas por parte de la Justicia del Trabajo por entender que muchas veces existían abusos por lo cual la relación se instrumentaba mediante una contratación de carácter fraudulenta.

La LCT estableció frente a ello, y como una garantía para el trabajador, un esquema de responsabilidad solidaria en el art. 29 bis, previéndose que "[e]l empleador que ocupe trabajadores a través de una empresa de servicios eventuales habilitada por la autoridad competente, será solidariamente responsable con aquélla por todas las obligaciones laborales y deberá retener de los pagos que efectúe a la empresa de servicios eventuales los aportes y contribuciones respectivos para los organismos de la Seguridad Social y depositarlos en término."

Ricardo Foglia (2013, p. 274) sostiene en este sentido que el art. 29 bis de la LCT conforma una responsabilidad objetiva de la empresa usuaria, ya que para que la misma opere solo basta con la existencia de una deuda (derivada del incumplimiento en el pago de cualquier crédito salarial o indemnizatorio) con el trabajador independientemente de la buena o mala fe del deudor solidario.

Desde la Justicia se sostuvo en forma correcta -en aquellos casos en los que se cumplían los presupuestos fácticos para que proceda la responsabilidad solidariaque "[m]ientras estas empresas cumplan acabadamente con los requisitos de ley, ninguna responsabilidad podría caber a la empresa usuaria, pues ambos sujetos de derecho estarían ajustando suactuación a la normajurídica que las habilita para llevar a cabo el negocio expuesto. Pero, si no se cumpliera alguno de esos requisitos, como por ejemplo que las tareas no fueran eventuales, entonces cae todo el andamiaje y se produce un verdadero fraude a la ley, porque se ha utilizado el art. 29 de la LCT como una cobertura generando una tensión entre la misma y el orden público laboral. En consecuencia, la usuaria deja de ser tal y pasa a ser empleadora. La empresa de servicios eventuales la acompaña en la solidaridad que, 
en este caso, el legislador la ha impuesto con fuente legal como sanción"10.

Esta era la posición asumida durante muchos años por la Justicia del Trabajo hasta que comenzó a considerarse que esa responsabilidad solidaria establecida por la Ley de Contrato de Trabajo en forma expresa, que colocaba a la empresa usuaria en calidad de responsable subsidiaria, pasaba a ser parte de una responsabilidad solidaria que colocaba a la empresa usuaria en calidad de verdadera empleadora y titular de la relación laboral, lo que dio lugar al dictado de sentencias contradictorias entre las diferentes Salas que integran la Cámara de Apelaciones del Trabajo.

Deestaformasecomenzóasostener, equivocadamente a nuestro entender, que en aquellos casos en los cuales el empleado prestara servicios en forma continuada para la empresa usuaria en labores propias de la actividad y del giro empresario, y no existiera una situación excepcional que motive su contratación, en realidad se estaba frente a una relación directa y permanente con el empresario que utilizó los servicios del trabajador, sin perjuicio de la responsabilidad solidaria del intermediario, invirtiéndose así los roles que asumían previamente la empresa de servicios eventuales y la empresa usuaria.

Frente a esta situación la Cámara Nacional de Apelaciones del Trabajo procedió a convocar a un fallo plenario"1 en el marco de la causa "Vázquez María Laura c/Telefónica de Argentina S.A. y Otro s/despido"12 a fin de determinar si en los casos en los cuales se extendía la responsabilidad solidaria a la empresa usuaria de los servicios debía considerarse la aplicación de las multas por empleo no registrado. En el mismo, con votación en mayoría, se resolvió que aquel contrato en el cual la contratación hubiera sido fraudulenta -ya sea por no existir un trabajo extraordinario o situación alguna que lo justificase, o cuando se hubieran sobrepasado los plazos previstos por la norma- se consideraría que la contratación era a tiempo indeterminado pero con el agravante de considerar que la empresa usuaria sería la real empleadora del trabajador, por lo que se convertía de esta forma la relación laboral como una relación laboral no registrada.

Las relaciones laborales no registradas en Argentina conllevan multas que multiplican las indemnizaciones laborales por despido sin aplicación de topes ${ }^{13}$. Pero además obligan a quien es considerado empleador a realizar todos los aportes y contribuciones a los organismos de la Seguridad Social por la totalidad de la relación laboral, aún cuando los mismos ya hubieran sido efectuados en forma completa por la empresa de servicios eventuales ${ }^{14}$.

Cabe destacar que en caso de que la empresa de servicios eventuales no estuviera inscripta por ante el registro correspondiente se considerará que esta es su empleadora directa, siendo alcanzada por los mismos efectos descriptos en el párrafo anterior.

Claramente, esta sentencia excede el marco de responsabilidad solidaria prevista en la Ley de Contrato de Trabajo, la cual tenía por fin asegurar el crédito del trabajador, frente a la posibilidad de que se utilizara empresas de servicios eventuales para evadir el cumplimiento de obligaciones laborales. Es claro que

\footnotetext{
${ }^{10}$ Cámara Nacional del Trabajo, Sala VII, expte N 5647/06, sentencia № 40741 del 7 de marzo de 2008 en el caso "Pazzaglini, Carlos c/ Sotyl SA y otro s/ despido".

${ }_{11}$ Un fallo plenario es una sentencia dictada con la participación de todos los integrantes de las Salas que componen la Cámara —en la actualidad son diez Salas de tres integrantes las que componen la Cámara Nacional de Apelaciones del Trabajo- y que tiene por objeto unificar la posición y evitar así que ante situaciones planteadas ante la Justicia en forma reiterada se culmine fallando en forma contradictoria, evitando así otorgar seguridad jurídica a las relaciones.

${ }^{12}$ Cámara Nacional de Apelaciones del Trabajo en pleno, 3/06/2010, fallo plenario № 323. Acta Nº 2.552.

${ }^{13}$ El régimen indemnizatorio argentino establece para una indemnización por antigüedad consistente en un salario por cada año de antigüedad, o fracción mayor a tres meses, tomándose como base de cálculo la mejor remuneración mensual normal y habitual devengada por el trabajador durante los últimos doce meses. Y las multas derivadas de una falta de registración o deficiente registración, aplicadas en su conjunto, pueden duplicar y hasta triplicar la eventual indemnización que le pueda corresponder a un empleado.

${ }_{14}$ Sobre el sinsentido del fallo nos hemos pronunciado en Tamagno (2010).
} 
la sentencia plenaria excede el marco de lo dispuesto por la norma, y resulta además contradictoria con el fin último de la norma, que no era otro que luchar contra el flagelo del empleo no registrado que regía al momento del dictado de la Ley 24.013 que era la que daba origen a estas multas.

Incluso, los jueces que se postularon por la posición mayoritaria hicieron referencia a frases tan vagas como ambiguas, utilizadas en forma abusivas muchas veces, como es "la intención del legislador" o "el espíritu de la norma". Pero tomando ambas expresiones como conceptos equivalentes podemos afirmar que la intención de los legisladores no fue la que finalmente terminaron adoptando en el decisorio y así fue reflejado oportunamente en el debate parlamentario ${ }^{15}$.

\section{El contrato eventual y la situación de licencias por enfermedad}

La contratación eventual posee diferentes particularidades también con relación a otros institutos, y este es el caso de las enfermedades, tanto aquellas ocasionadas en el desarrollo de las tareas laborales como aquellas que no poseen relación causal con el trabajo.

En Argentina existe un tratamiento diferenciado para las enfermedades inculpables que son aquellas enfermedades que no poseen relación causal con las tareas desarrolladas en la empresa y otro diferente para las enfermedades profesionales ${ }^{16}$ que son aquellas que sí poseen vinculación con las tareas desempeñadas por el trabajador a las órdenes de su empleado.

En el caso de las enfermedades inculpables la LCT establece el pago de una licencia con cancelación de salarios por un tiempo determinado -el cual oscila entre tres meses y doce meses - según la antigüedad y las cargas de familia que pudiera tener. A nuestro entender, en el caso del contrato de trabajo eventual esta licencia se otorgará hasta la finalización del evento por el cual fue contratado, y así ha sido sostenido por la Justicia del Trabajo al decir que "del juego armónico de los principios que informan la contratación eventual, los deberes derivados del estado de enfermedad se limitan al tiempo de duración del contrato (conf. Hernán Bernasconi «El contrato de trabajo eventual, caracterización y efectos» LT XXVII pág. 225), ya que no resulta compatible con el principio en que se funda el instituto, la conservación del empleo tres o seis meses cesada la causa que motivara el contrato eventual con derecho al cobro de salarios, en tanto excede lo acordado, como asimismo la expectativa del trabajador al concertar este tipo de contratos"17.

Sin embargo, la situación es diferente en el caso de las enfermedades profesionales. El régimen de Riesgos del Trabajo establece un esquema de otorgamiento de prestaciones dinerarias y en especie en las cuales la

\footnotetext{
${ }^{15}$ Ello puede observarse del propio dictamen de la mayoría de Cámara de Diputados de aquel entonces en donde se sostuvo que "[e]n el dictamen que propiciamos podemos distinguir tres líneas fundamentales que sustentan la estrategia del proyecto. En la primera parte se establece un ingenioso sistema de premios y castigos destinados a alentar el blanqueo de las relaciones laborales sumergidas en la clandestinidad, que generará la incorporación de una parte importante de trabajadores al sistema de seguridad social y de las empresas al pago de sus cargas impositivas" (Diario de Sesiones, Cámara de Diputados, $37^{a}$ reunión, septiembre 26 y 27 de 1991 , primera parte, p. 3156).

${ }_{16}^{16}$ Mal llamadas "profesionales", y que a nuestro entender deberían considerarse como "laborales".

17 Cámara Nacional del Trabajo, Sala II, expte N 11147/00, sentencia N 89281 del 30 de abril de 2001 en el caso "Rolón, Fabian c/ Asistencia Médica Social Argentina SA s/ despido".
} 
aseguradora de riesgos del trabajo abona una suma sustitutiva del salario - a partir del décimo día posterior a la licencia - y brinda a su vez prestaciones médicas.

En el caso del contrato eventual la aseguradora de riesgos del trabajo deberá continuar otorgando prestaciones médicas hasta el momento de la alta médica ya que resulta claro que la finalización del evento no puede ser un elemento que conlleve el abandono del paciente por la mera extinción del vínculo laboral. Esto mismo sucede en el caso de la extinción del contrato a tiempo indeterminado, en donde más allá de la extinción de la relación laboral, la atención médica iniciada durante la relación deberá continuar brindándose. Pero respecto de las prestaciones dinerarias, que conforman la sustitución del pago salarial por parte de la aseguradora, éstas se extinguen también con el agotamiento del objeto del contrato.

\section{La prueba del contrato eventual}

En materia probatoria lo que define el carácter extraordinario del contrato eventual no es solamente el tiempo de duración, sino el tipo de funciones cumplidas, y si no se ha probado que las tareas llevadas a cabo por el trabajador hayan revestido el carácter de eventualidad, la figura de excepción no puede aplicarse.

Pero además deben estar cumplidos todos los requisitos formales, toda vez que para considerar válido un contrato eventual, como excepción al principio general de indeterminación del plazo, es necesario que se cumplan todos los requisitos exigidos por la ley, los cuales son acumulables y no alternativos.

De esta forma, una vez verificado el cumplimiento de todos los requisitos formales, es el empleador quien tiene la carga de probar que el contrato reviste la modalidad de eventual, pues cabe poner de resalto que en materia laboral debe primar siempre la realidad material por sobre la formal, es decir la verdad de los hechos sobre la apariencia o por encima de los acuerdos - plasmados en los requisitos formales-, por lo que más allá del ropaje que las partes le hayan intentado dar a la relación laboral se deberá probar mediante hechos concretos los extremos que se han alegado para llevar adelante este tipo de contratación laboral excepcional. Como sostenía Julio J. Martínez Vivot (1987): "Como se ha dicho en una sentencia, el carácter eventual de un contrato de trabajo, cuya prueba está a cargo de quien la invoca, no depende sólo de la denominación que le den las partes, ni de su posible accesoriedad entre las fuentes de subsistencia del propio trabajador, sino de su relación con exigencias extraordinarias y transitorias del establecimiento o servicios extraordinarios determinados de antemano" (p. 119).

La naturaleza del contrato eventual dependerá entonces de una situación fáctica que permita demostrar fehacientemente que los servicios prestados por el trabajador obedecieron a exigencias transitorias y extraordinarias o a servicios extraordinarios determinados de antemano al momento de contratar, conforme lo exige el art. 99 de la LCT. Así, aquel empleador que invoque la existencia de un contrato de trabajo eventual tendrá a su cargo el demostrar en qué han consistido las necesidades extraordinarias y transitorias que se utilizaron para fundar la contratación, cuáles han sido las razones por las cuales se necesitó contratar trabajadores eventuales y finalmente que los servicios extraordinarios determinados de antemano en la contratación han sido debidamente cumplidos.

Como se expuso anteriormente, el contrato de trabajo eventual debe ser celebrado por escrito, estableciéndose las cláusulas que describan las formalidades propias del contrato, pero - sobre todo- donde se describan las tareas eventuales para los cuales el trabajador fue contratado, para así poder conocer que el vínculo laboral se extinguirá cuando concluya la tarea que le es encomendada. 
Será el empleador quien deba demostrar que el trabajador ha sido contratado para la satisfacción de determinadas obligaciones o servicios, identificados o individualizados previamente, que por sus características se encuentran fuera de las labores que habitualmente presta la empresa, o que siendo propios de la empresa presenta características de exigencias transitorias (picos de trabajo, realización de una obra determinada que excede el marco habitual de trabajo de la empresa).

Lo importante será probar principalmente lo extraordinario del trabajo, es decir, que realmente se trata de una situación que no implica un crecimiento sino una situación estacional que la habilita a poder contratar a personal a sabiendas que solo lo necesitará por ese período de tiempo.

Ahora bien, si la empresa tiene esta necesidad extraordinaria derivada de un crecimiento propio de su giro que generan mayor demanda nos encontramos en ese caso frente a circunstancias ordinarias y normales del mercado en el cual se desarrolla, en esta situación cedería el principio extraordinario al que hemos hecho referencia.

"La prueba de la existencia de un contrato de trabajo eventual debe ser estricta, por resultar una situación de excepción dentro del ordenamiento jurídico laboral que privilegia la permanencia de toda relación de trabajo"18.

El mismo régimen probatorio debe aplicarse a aquellas contrataciones de empresas de servicios eventuales, todos los mismos extremos deben ser demostrados para que el contrato de trabajo eventual no sea considerado fraudulento.

Así ha sido clara la Justicia del Trabajo al sostener que "[n]i la celebración por escrito de un contrato de trabajo eventual, ni la intermediación de una empresa de servicios temporarios inscripta en el registro que lleva el Ministerio de Trabajo eximen de la prueba de la necesidad objetiva eventual, justificativa del modelo. Ello así pues en nuestro ordenamiento jurídico no basta el acuerdo de voluntades sanas y la observancia de las formalidades legales, para generar un contrato de trabajo de plazo cierto o incierto. Debe mediar también una necesidad objetiva del proceso productivo que legitime el recurso de esas modalidades"19. De esta forma se ratifica la primacía de lo material por sobre lo formal que rige como rector en el derecho laboral argentino.

\section{El contrato eventual y su relación con el derecho de huelga}

Se prohíbe expresamente la contratación de personal a través de la figura de contrato eventual para aquellos supuestos de reemplazos de empleados que se encuentren ejerciendo una medida de huelga o de acción directa ${ }^{20}$, esta prohibición se presenta así como consustancial al derecho de huelga y en caso de que el empleador avance llevando así este tipo de contrataciones estará incurriendo en una infracción que podría ser penalizada por la autoridad administrativa del trabajo, pudiendo ser encuadrada desde el análisis

\footnotetext{
${ }^{18}$ Cámara Nacional del Trabajo, Sala X, expte. № 12286/04, sentencia № 15915 del 29 de febrero de 2008 en el caso "Agostino, Diego c/In Store Marketing SRL y otros s/despido".

${ }^{19}$ Cámara Nacional del Trabajo, Sala IV, expte N³513/06, sentencia Nº 93339 de fecha 20 de mayo de 2008 en el caso "Paez, Luis c/ IONICS SA s/ despido".

${ }^{20}$ La prohibición de llevar adelante este tipo de contrataciones ya se encontraba presente en el antiguo art. 244 LCT: "El empleador no podrá concertar durante el tiempo de duración de la huelga u otras medidas de acción directa aprobadas por la organización sindical pertinentes, nuevos contratos de trabajo, ni adoptar medidas disciplinarias en su contra, ni alterar la situación condición en que se encontrara revistando en la empresa".
} 
mismo de la Ley de Entidades Sindicales como del Pacto Federal de Empleo.

Esta figura nace a partir de que se contrataban en la antigüedad personal a los efectos de convertirse en "rompehuelgas". Los rompehuelgas eran sujetos contratados a los efectos de ocupar los puestos de trabajo que los huelguistas dejaban sin atención producto de la medida de acción directa adoptada. De esta forma se lograba que la huelga perdiera virtualidad y se cumpliera con la jornada de trabajo con normalidad, no afectándose el ritmo de la producción o actividad de una empresa. Se trataba de lo que hoy se conoce como práctica desleal por parte de la empresa.

Pero esta prohibición no es exclusiva de la norma argentina, sino que así ha sido puesto a consideración por la propia Organización Internacional del Trabajo (OIT, 2006), la cual ha sostenido que "[l]a contratación de trabajadores para romper una huelga en un sector, al que no cabría considerarse como sector esencial en el sentido estricto del término para que pudiera prohibirse la huelga, constituye una grave violación de la libertad sindical" (Informe caso número 1282, párrafo 419), y "[s] i una huelga es legal, el recurso de utilización de mano de obra no perteneciente a la empresa con el fin de sustituir a huelguistas, por una duración indeterminada, entraña el riesgo de violación del derecho de huelga que puede afectar el libre ejercicio de los derechos sindicales" (Informe caso número 1543, párrafo 93).

Se podría configurar la contratación de personal para cubrir a otros empleados que se encuentran tomando una medida de acción directa como una práctica desleal en términos sindicales, toda vez que de esta forma se neutraliza el objeto de la huelga que no es otro que el de provocar un daño - tolerado por el sistema - a fin de poder manifestarse y reclamar el cumplimiento de las normas que entiende el colectivo de trabajadores se encuentran vulneradas o están siendo violadas.

Y es aquí donde el contrato de carácter eventual podría presentarse como una alternativa normativamente regulada para poder cubrir estos puestos de trabajo debido a la situación extraordinaria que la huelga genera para una empresa. Por este motivo el legislador se ha encargado expresamente de evitar que se utilice esta figura contractual para cubrir el trabajo objeto del paro de actividades derivado de la huelga.

\section{La diferencia del contrato eventual con otros contratos}

El contrato eventual comparte con otros contratos laborales la característica extraordinaria de temporaneidad en cuanto a su duración, y así comparte esta especie contractual con el contrato a temporada y con el contrato a plazo fijo, donde las diferencias entre los mismos se encuentran en las particularidades.

Quizás el contrato de trabajo eventual con el que más se confunde es con el contrato a plazo fijo, y solo se lo utiliza en las contrataciones cuando intermedia una empresa de servicios eventuales.

Por ello, en la práctica el contrato a plazo fijo se utiliza para regular contrataciones que deberían ser encuadradas por intermedio del contrato eventual, lo que conlleva luego a que, al finalizar el período pactado en el contrato, se debe proceder a realizar una renovación del mismo en virtud de que no se ha agotado el objeto del contrato para el cual fue contratado. En el contrato de trabajo eventual y en el contrato a plazo fijo se comparte la limitación temporal como característica, pero lo distintivo, y así nace de la técnica legislativa utilizada por el legislador, es la incertidumbre o indeterminación del plazo que opera en el contrato eventual a diferencia de la certeza que se tiene en el contrato a plazo fijo. Sin embargo, esta diferenciación no es tan aceptada por todos, algunos autores como Eduardo Álvarez (2005) han sostenido que "el contrato de trabajo eventual es 
un contrato a plazo" (pp. 202-203) sobre la base de que existe solo una imprecisión diaria pero que tiende a regular un mismo tipo contractual.

Y esto ha sido parte de tratamiento judicial cuando se ha sostenido que "[s]i las partes suscribieron un acuerdo al que denominaron "contrato eventual», en cuya cláusula primera se establece que su vigencia se prolongará de acuerdo al tiempo que conlleve la licencia vacacional del personal de tiendas, desde el día 6 de enero al 31 de mismo mes, expresando que el mismo finalizará en tal fecha y no será extendido más allá de la fecha expresada, nos hallamos frente a un contrato a plazo fijo y no eventual. Ello así, toda vez que, de la formulación adoptada, resulta un plazo cierto de finalización del vínculo que remite al art. 93 LCT, contraponiéndose a la caracterización prevista en el art. 99 del mismo cuerpo legal que para el trabajo eventual contempla aquellos casos en que «...no pueda preverse un plazo cierto para la finalización del contrato...»»21.

Pero otro contrato con el cual normalmente se confunde en cuanto a su aplicación es con el contrato de temporada. Sin embargo, el contrato de temporada, regulado en el art. 96 de la LCT, es un contrato por tiempo indeterminado, pero con prestaciones discontinuas. Los trabajos de temporada se dan en aquellos supuestos en que la actividad propia del giro normal de la empresa o explotación se cumple en determinadas épocas del año solamente y está sujeto a repetirse en cada ciclo en razón de la naturaleza de la actividad.

Así lo ha entendido la Justicia del Trabajo al sostener que "[l]a necesidad que da origen a la contratación de temporada no se agota con el transcurso de la misma sino que, por el contrario, a diferencia de la que caracteriza la modalidad "eventual", está sujeta a repetirse cíclicamente. Desde tal perspectiva el contrato de temporada no puede caracterizarse como una excepción al contrato de trabajo por tiempo indeterminado, por lo que no resultan atendibles los argumentos relativos a que dicha modalidad deba formalizarse conforme los recaudos establecidos en el art. 90 LCT, para los contratos a plazo determinado"22.

\section{Conclusión}

Podríamos iniciar esta conclusión sosteniendo que el contrato de trabajo eventual se presenta como un contrato de carácter excepcional que tiene su mayor aplicación en los últimos 30 años.

No quedan dudas que nos encontramos frente a un contrato laboral de carácter excepcional, en donde se ha buscado dar una salida no gravosa para un empleador que, por una circunstancia extraordinaria, debe contratar personal para atender la misma sin tener que asumir los costos luego de la extinción de la relación laboral. Esa fue al menos la intención del legislador al momento del dictado de la norma, como una forma así de impulsar la contratación de mano de obra y dar empleo a un número mayor de personas.

Recordemos que la Ley 24.013 y su reglamentación fue dictada en un momento en el que preponderaba el concepto de apertura económica, y para ello se imponía que el derecho del trabajo debía acompañar esta nueva era donde los negocios se comenzaban a internacionalizar - como una manifestación del período

${ }^{21}$ Cámara Nacional del Trabajo, Sala IX, expte. №21069/05, sentencia N 13905 del 28 de diciembre de 2006 en el caso "Majul, María c/Día Argentina SA s/ despido".

22 Cámara Nacional del Trabajo, Sala II, expte. № 1286/07, sentencia № 95828 del 12 de febrero de 2008 en el caso "Ormachea, Guillermo c/ Asoc. Civil Club Italiano s/ despido". 
de globalización que estaba naciendo - y que imponía a los países generar mayor competitividad.

Es en este marco histórico en donde el contrato de trabajo eventual - con otras modalidades contractualescomienza a adquirir mayor importancia y aplicación en el marco de las relaciones laborales.

No obstante, esta modalidad de contratación genuina en sí misma presentó su faz negativa, y como en toda contratación laboral, y más aún en estos contratos en donde tienen como objeto situaciones muy particulares, surgieron abusos por parte de los empleadores mereciendo una evolución jurisprudencial que se ha iniciado con el dictado de sentencias condenatorias por el abuso realizado sobre esta figura.

Con relación a ello, el mayor abuso se ha dado con la utilización de empresas de servicios eventuales en donde se utilizaba a la empresa como mera intermediaria fraudulenta en la relación laboral, a punto tal que la Justicia Nacional del Trabajo prestó especial atención sobre el problema que se había suscitado, y - a nuestro extender extralimitándose en el alcance de la normadictó un fallo plenario en donde resolvió que la relación entre el empleado de la empresa de servicios eventuales y la empresa usuaria era la única relación laboral, siendo la empresa usuaria el real empleador e imponiendo las multas por trabajo no registrado.

Por ello, no quedan dudas que el contrato de trabajo eventual es un contrato legítimo que utilizado en forma lícita se convierte en una herramienta muy interesante para empresas que deben atender alguna circunstancia extraordinaria, evitándose así recargar de tareas al personal o contratar personal y tener que despedirlo debiendo abonar las indemnizaciones de ley correspondientes.

\section{Referencias}

Alonso Olea, M. \& Casas Baamonde, M.E. (1987). Derecho del Trabajo (10a ed.). Madrid: Universidad Complutense. Álvarez, E. (2005). Reflexiones críticas acerca del contrato de trabajo eventual. Revista de Derecho Laboral, 2005-2, 199-210.

Cruz Villalón, J. (2019). Compendio de Derecho del Trabajo. Madrid: Tecnos.

De Litala, L. (1946). El contrato de trabajo (2a ed.) (trad. Santiago Sentís Melendo). Buenos Aires: Lopez \& Etchegoyen. Etala (h), J.J.; Etala, C.A.; De Virgilis, M.A. (1992). Análisis práctico de la Ley de Empleo. Buenos Aires: La Ley. Fernández Madrid, J.C. (2012). Ley de Contrato de Trabajo comentada y anotada (2a ed.). Buenos Aires: La Ley. Foglia, R.A. (2013). De los sujetos del contrato de trabajo. En J. Rodríguez Mancini (Dir.). Ley de Contrato de Trabajo.

Comentada, anotada y concordada. Tomo II (2a ed.). Buenos Aires: Thomson Reuters - La Ley.

Martínez Vivot, J.J. (1987). Elementos de Derecho del Trabajo y de la Seguridad Social. Buenos Aires: Astrea.

Mercarder Uguina, J.R. (2018). Lecciones de Derecho del Trabajo. Valencia: Tirant lo Blanch.

OIT (2006). Libertad Sindical. Recopilación de decisiones y principios del Comité de Libertad Sindical del Consejo de Administración de la OIT. Recuperado de: https://www.ilo.org/wcmsp5/groups/public/---ed_norm/---normes/ documents/publication/wcms_090634.pdf [Fecha de consulta: 15 de septiembre de 2020].

Ramirez Gronda, J. (1964). El contrato de trabajo. En M.L. Deveali (dir.). Tratado de derecho del trabajo (pp. 407-460), Buenos Aires: La Ley.

Real Academia Española. (2010). Diccionario de la Lengua Española (23a ed.). Recuperado de: https://dle.rae.es/ [fecha de consulta: 16 de septiembre de 2020].

Tamagno, L.F. (2010). A propósito del plenario “Vásquez, María Laura c. Telefónica de Argentina S.A. y otro s/despido". El Derecho, 238, 602-607.

Vázquez Vialard, A. (1978). Derecho del trabajo y de la seguridad social. Buenos Aires: Astrea. 


\section{Jurisprudencia}

Cámara Nacional del Trabajo, Sala II, expte № 11147/00, sentencia № 89281 del 30 de abril de 2001 en el caso "Rolón, Fabian c/ Asistencia Médica Social Argentina SA s/ despido".

Cámara Nacional del Trabajo, Sala V, expte n 19676/02, sentencia № 68396 del 28 de abril de 2006 en el caso "Aliotta, María c/ Citibank NA y otro s/ despido".

Cámara Nacional del Trabajo, Sala X, expte. № 2/05, sentencia № 14407 del 20 de junio de 2006 en el caso "González, Víctor c/ Río de las Vueltas SRL y otro s/ despido".

Cámara Nacional del Trabajo, Sala IX, expte. № 21069/05, sentencia № 13905 del 28 de diciembre de 2006 en el caso "Majul, María c/Día Argentina SA s/ despido".

Cámara Nacional del Trabajo, Sala V, expte n²5232/03, sentencia № 69183 del 13 de febrero de 2007 en el caso "Jiménez, Patricia c/Apoyo laboral SRL s/despido".

Cámara Nacional del Trabajo, Sala II, expte. № 1286/07, sentencia № 95828 del 12 de febrero de 2008 en el caso "Ormachea, Guillermo c/ Asoc. Civil Club Italiano s/ despido".

Cámara Nacional del Trabajo, Sala X, expte. № 12286/04, sentencia № 15915 del 29 de febrero de 2008 en el caso "Agostino, Diego c/In Store Marketing SRL y otros s/despido".

Cámara Nacional del Trabajo, Sala VII, expte № 5647/06, sentencia № 40741 del 7 de marzo de 2008 en el caso "Pazzaglini, Carlos c/ Sotyl SA y otro s/ despido".

Cámara Nacional del Trabajo, Sala IV, expte №3513/06, sentencia № 93339 de fecha 20 de mayo de 2008 en el caso "Paez, Luis c/ IONICS SA s/ despido".

Cámara Nacional de Apelaciones del Trabajo en pleno, 3/06/2010, fallo plenario № 323. Acta № 2.552. 